\title{
The Impact of Blindness on the Oral Health and the Perceived Need to Seek Treatment in a Community of Maltese Older Adults
}

\author{
Schembri A*, Borg W, Santucci D and Attard N \\ Department of Oral Rehabilitation and Community Care, Faculty of Dental Surgery, University of Malta
}

Received: June 01, 2018; Published: June 14, 2018

*Corresponding author: Schembri A, Deparment of Oral Rehabilitation and Community Care, Faculty of Dental Surgery, University of Malta, Europe

\section{Abstract}

Objectives: The aim of this pilot study was to explore the impact of blindness on oral health in a convenient sample of a group of legally blind, older adults.

Methods: Twenty-six (26) totally blind people were interviewed. Five questionnaires were used: OHIP-14, GOHAI, Denture Satisfaction Questionnaire, the maintenance of oral health and the recognition of the need to seek treatment. The data was analysed using Spearman Correlation Coefficient.

Results: Majority of subjects recognized the importance of health check-ups and relied on support to seek checkups. Subjects reported their oral health to be good. The presence of removable dentures was associated with poorer oral-health related quality of life in the subjects. Interestingly although subjects were legally blind, $50 \%$ of sample reported not being pleased with the looks of their mouth or dentures, suggesting that negative issues related to the oral health were expressed in non-specific or -related terms.

Conclusion: This area of research deserves a more extensive investigation that will include more individuals as well as a dental examination. Visually impaired older adults may give more priority to their disability than their oral care therefore interdisciplinary action will empower the older adult to seek the necessary care required from various dental, social and medical professionals.

\section{Introduction and Literature Review}

Visual impairment is a global problem. A 1995 WHO/PBL databank estimated that there are 38 million blind people in the world [1]. In 1997, the WHO had estimated that approximately 45 million people were blind, and almost $60 \%$ of these people were more than 60 years old [2]. This figure has changed in recent years to an estimated 39 million blind and around $82 \%$ of these individuals are aged 50 years or over [3]. The major cause of blindness remains cataracts in middle and low-income countries [3]. Ocular degeneration secondary to diabetes mellitus is the second most common cause [2]. A rising number of people suffering from diabetes mellitus is likely in the coming years due to increased life expectancy, therefore increasing the risk of ocular damage due to this disease in the future [2]. This increase in life-expectancy also means an increase in age-related visual impairment cases too [3].

According to the American Foundation for the Blind, the clinical parameters to define blindness from a legal perspective (legal ly blind) correspond to a central visual acuity of 20/200 or less in the better eye and/or a visual field of 20 degrees or less. People diagnosed with legal blindness usually still possess some vision [4] Total blindness is defined as the inability to see anything at all with either eye [4]. Several barriers to dental care are present for people who are visually impaired and more so for those who are blind [2]. Compounding this problem is the fact that visual impairment occurs mainly in the older adult population; individuals who may already be finding problems to live independently [5]. In fact, the first of these barriers may probably be physical access to dental care since they depend on carers to accompany them to the clinic. Another barrier could be access to printed information about dental health where the blind person once again depends on his/her carers to make them aware of any relevant dental information.

Routine daily personal dental hygiene such as tooth brushing might be another barrier for blind individuals, the use of daily 
mouthwash may be recommended to compensate for the lack of individual hygiene assessment. Very few population-based studies have attempted to study the impact of blindness on everyday tasks. Furthermore, when such studies are carried out, function tests offer a different picture from self-reported function on several different levels. Therefore, they do not really represent an accurate picture of the reality [6]. Even a simple task such as placing toothpaste on the toothbrush might be a barrier to blind individuals. An incorrect, traumatic, tooth brushing technique might be the cause of early onset periodontal disease [7]. Fear and apprehension of the dental setting could be another barrier to oral care, as dental treatment can be perceivably threatening and invasive, and a visual impairment such as blindness may accentuate this. This fear of the dentist could be a possible reason why individuals with a visual impairment seek dental treatment only when they are in pain [2].

\section{Oral Health Impact Profile-14, General Oral Health As- sessment Index, Denture Satisfaction Questionnaire}

The Oral Health Impact Profile (OHIP) was developed by Slade and Spencer in 1994 to assess the effect of oral disorders on daily life. Each statement is answered by one of [5] responses in the form of a Likert Scale ranging from 'Very Often' having the highest score (score 4) to 'Never' (score 0) with the lowest score. Interviewees may also opt for a 'don't know' answer for each statement. If more than nine questions are left blank or marked as 'don't know', the questionnaire is discarded.8 The OHIP-14 developed in 1997, is a shortened version of the OHIP, using [2] questions from each sub-section based on Locker's model of oral health which include functional limitation, pain, psychological discomfort, physical disability, psychological disability, social disability and handicap [9]. OHIP-14, being shorter, probably improves patient compliance. The General Oral Health Assessment Index (GOHAI) was developed by Atchison and Dolan (1990) for a self-reported assessment on the oral health status of older adults. It contains 12 questions from 3 dimensions including physical function, psychosocial function and pain and discomfort. All questions asked are regardless of dentate status and use of prosthesis [10].

The Denture Satisfaction Questionnaire aims at evaluating prosthetic outcomes from a physiological, physical and psychosocial perspective. Maxillary and mandibular dentures are rated on a Likert scale for general satisfaction, retention, comfort, stability, appearance, ability to speak and occlusion [11]. In Malta, English is well-versed by 36,853 (48\%) individuals over 60 years of age, whilst 19,525 (25\%) individuals over 60 years of age do not speak English at all. On the other hand, the large majority of individuals, $(72,522$ or $94 \%)$ over 60 years of age residing in Malta, speak Maltese fluently [12]. As the vast majority of older adults speak Maltese more than English, a validated Maltese version for OHIP-14, GOHAI and Denture Satisfaction Questionnaires was developed previously, and utilized in this study [13].

\section{Aim}

The aim of this pilot study was to explore the impact of blindness on oral health as measured by OHIP-14, GOHAI and Denture Satisfaction Questionnaires in a convenient sample of a group of older adults legally blind people who regularly attend the day centre for the blind in Malta.

\section{Methodology}

The sample for this preliminary was a convenient sample of all the individuals who were currently registered voluntarily to attend the governmental institution for the blind. This place is a dedicated unit for the blind individuals who meet regularly on a weekly basis. Twenty-six (26) totally blind individuals were interviewed to complete five questionnaires. Three of these questionnaires were: Oral Health Impact Profile-14 (OHIP-14), General Oral Health Assessment Index (GOHAI), and the Denture Satisfaction Questionnaire. Another two structured interviews had two main themes: the maintenance of oral health and the recognition of the need to seek treatment. Seventeen (17) of these individuals were interviewed personally by two general dental practitioners, in the institutional building whilst the remaining nine (9) blind individuals (previous attendees of the blind centre) were interviewed over a telephone call, since they no longer attend as they are now homebound. The response rate was $100 \%$. The data was collated in digital format and Spearman Correlation Coefficient was analysed using SPSS statistical software. Statistical significance was set at $p<0.05$.

\section{Results}

\section{Demography}

Twenty-three percent $(\mathrm{N}=6)$ females and $77 \%(\mathrm{~N}=20)$ males took part in the study. Their ages ranged from 52 to 85 with a mean of 63. Twenty-three percent $(\mathrm{N}=6)$ individuals lived alone while $77 \%(\mathrm{~N}=20)$ lived with family members. Glaucoma $(27 \%)$ was cited as the main cause of blindness, followed by trauma (19\%) and diabetes (15\%). Other causes for blindness were retinal detachment, rubella, retinitis pigmentosis and congenital defects. Forty-six percent $(\mathrm{N}=12)$ lost their eyesight at 20 + years of age, $31 \%(\mathrm{~N}=8)$ were certified blind at $10-20$ years, $15 \%(\mathrm{~N}=4)$ at $1-5$ years, while only $8 \%(\mathrm{~N}=2)$ were blind at birth. The majority of participants $(65 \%)$ were not adept at reading Braille.

\section{Maintaining Oral Health and Recognising the Need to Seek Treatment}

Most individuals, 92\% ( $\mathrm{N}=24)$ recognize the importance of regular health check-ups. However $62 \%(\mathrm{~N}=16)$ identified transport as the major barrier to seek dental treatment. The majority of individuals were treated private dentist $(65 \%, \mathrm{~N}=17)$, and most $(62 \%$, $\mathrm{N}=16$ ) sought help from family members to buy dental products and for means of transport for dental visits. The majority of individuals $(62 \%, \mathrm{~N}=16)$ claimed that they do not currently need any dental treatment. When questioned about oral health maintenance, $65 \%(\mathrm{~N}=17)$ claim that they brush their teeth. Overall, $46 \%(\mathrm{~N}=12)$ brush their teeth twice daily. Most individuals, 92\% ( $\mathrm{N}=24)$, claim that they do not need any help with brushing their teeth. When asked whether they had ever been told how to brush their teeth, only $15 \%(\mathrm{~N}=4)$ claimed that they had been instructed at least once in their life before they had lost their vision. All individuals claimed they use a manual toothbrush. The majority of individuals (92\%, $\mathrm{N}=24$ ) do not use any mouthwash which would have been other- 
wise beneficial to reach areas where plaque would have remained due to lack of direct vision.

\section{HIP-14}

The response rate was $100 \%$. The average OHIP-14 score obtained was 5.7 which from a possible worst score of 56, indicates a very good oral health-related quality of life. The best obtainable score for 0HIP-14 is 0 , of which $15.4 \%(\mathrm{~N}=4)$ of participants obtained. The worst score obtained is 23 from a possible 56 . The mode and the median were 3.0 once again indicating a good oral health-related quality of life (Tables 1 \& 2). 38.5\% ( $\mathrm{N}=10)$ of participants had a score worse than the average score of 5.7 indicating a worse oral health-related quality of life than the rest of the par- ticipants. None of the 10 participants $(\mathrm{N}=10)$, who had an OHIP-14 score higher than the average of 5.7 had dentures possibly indicating a poor oral health status such as caries and periodontal disease. Table 3 indicates that with reduced denture satisfaction scores, the oral health-related quality of life also decreases (increasing OHIP14) however this was not statistically significant ( $p>0.05)$ as sample size was too small. $34.6 \%$ of individuals $(\mathrm{N}=9)$, reported 'very often', 'often' and 'occasionally', indicating worst oral health-related quality of life in questions 3 (painful episodes) and 4 (uncomfortable eating). It is interesting to note that $15.4 \%(\mathrm{~N}=4)$ stated that they are fairly often conscious because of their teeth, mouth or dentures due to their visual impairment with $11.5 \%(\mathrm{~N}=3)$ claiming that life in general was less satisfying.

Table 1: The OHIP-14 results as a percentage of each score in all participants.

\begin{tabular}{|c|c|c|c|c|c|}
\hline 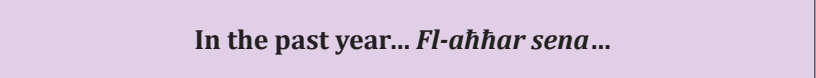 & $\begin{array}{c}\text { Very Often/ } \\
\text { Spiss Hafna (\%) }\end{array}$ & $\begin{array}{c}\text { Fairly Often/ } \\
\text { Spiss (\%) }\end{array}$ & $\begin{array}{c}\text { Occasionally/ } \\
\text { Kultant(\%) }\end{array}$ & $\begin{array}{c}\text { Hardly Ever/ } \\
\text { Rari(\%) }\end{array}$ & $\begin{array}{l}\text { Never/ } \\
\text { Qatt(\%) }\end{array}$ \\
\hline 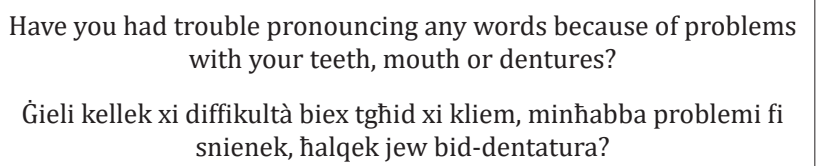 & 3.8 & 0 & 3.8 & 11.5 & 80.8 \\
\hline 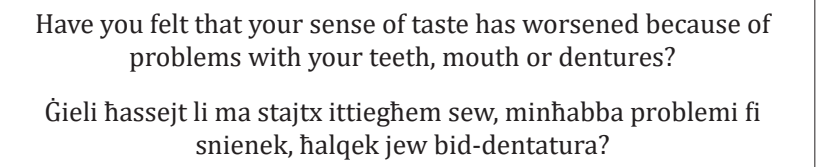 & 0 & 0 & 11.5 & 23.1 & 65.4 \\
\hline $\begin{array}{l}\text { Have you had painful aching in your mouth? } \\
\text { Ġieli kellek ugigh qawwi f' halqek? }\end{array}$ & 0 & 3.8 & 30.8 & 23.1 & 42.3 \\
\hline $\begin{array}{l}\text { Have you found it uncomfortable to eat any foods because of prob- } \\
\text { lems with your teeth, mouth or dentures? } \\
\text { Gieli hassejtek skomdu/a tiekol xi ikel, minћabba problemi fi } \\
\text { snienek, halqek jew bid-dentatura? }\end{array}$ & 0 & 15.4 & 19.2 & 19.2 & 46.2 \\
\hline $\begin{array}{l}\text { Have you been self-conscious because of your teeth, mouth or } \\
\text { dentures? } \\
\text { Gieli hassejtek konxju bi snienek, halqek jew bid-dentatura? }\end{array}$ & 3.8 & 15.4 & 0 & 3.8 & 76.9 \\
\hline $\begin{array}{l}\text { Have you felt tense because of problems with your teeth, mouth or } \\
\text { dentures? } \\
\text { Gieli kont anzjuż minћabba problemi fi snienek, halqek jew } \\
\text { bid-dentatura? }\end{array}$ & 0 & 3.8 & 3.8 & 11.5 & 80.8 \\
\hline $\begin{array}{l}\text { Has your diet been unsatisfactory because of problems with your } \\
\text { teeth, mouth or dentures? } \\
\text { Thoss li l-ikel ta' kuljum mhux jgћogbok biżżejjed minћabba prob- } \\
\text { lemi fi snienek, halqek jew bid-dentatura? }\end{array}$ & 0 & 0 & 3.8 & 30.8 & 65.4 \\
\hline $\begin{array}{l}\text { Have you had to interrupt meals because of problems with your } \\
\text { teeth, mouth or dentures? } \\
\text { Gieli kellek tieqaf f'nofs ikla, minћabba problemi fi snienek, halqek } \\
\text { jew bid-dentatura? }\end{array}$ & 0 & 0 & 3.8 & 3.8 & 92.3 \\
\hline 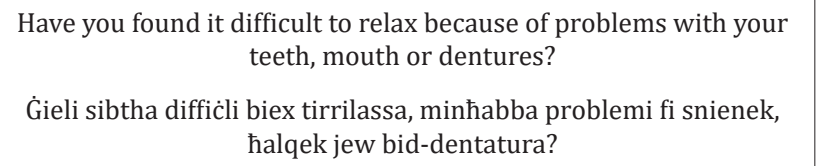 & 0 & 0 & 3.8 & 0 & 96.2 \\
\hline $\begin{array}{l}\text { Have you been a bit embarrassed because of problems with your } \\
\text { teeth, mouth or dentures? } \\
\text { Gieli hassejtek imbarazzat/a, minћabba problemi fi snienek, halqek } \\
\text { jew bid-dentatura? }\end{array}$ & 0 & 0 & 0 & 11.5 & 88.5 \\
\hline
\end{tabular}




\begin{tabular}{|c|c|c|c|c|c|}
\hline 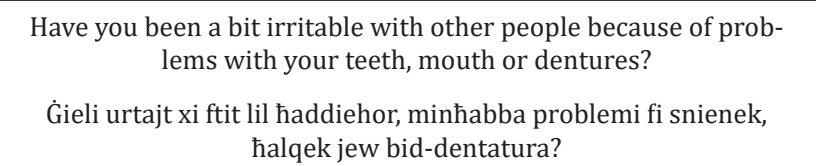 & 0 & 0 & 0 & 3.8 & 96.2 \\
\hline 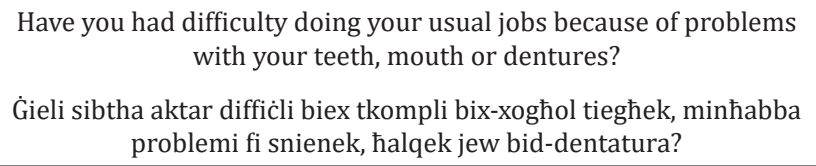 & 0 & 0 & 3.8 & 11.5 & 84.6 \\
\hline 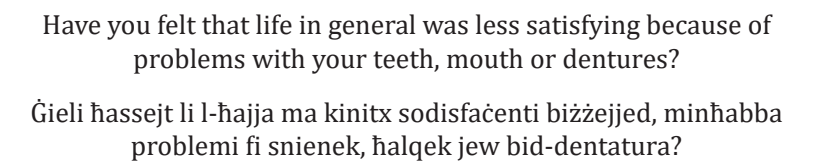 & 0 & 11.5 & 3.8 & 26.9 & 57.7 \\
\hline $\begin{array}{l}\text { Have you been totally unable to function because of problems with } \\
\text { your teeth, mouth or dentures? } \\
\text { Gieli hassejt li ma stajtx tkampa xejn mal-hajja ta' kuljum minћabba } \\
\text { problemi fi snienek, halqek jew bid-dentatura? }\end{array}$ & 0 & 0 & 3.8 & 19.2 & 76.9 \\
\hline
\end{tabular}

Table 2: The GOHAI results as a percentage of each score.

\begin{tabular}{|c|c|c|c|c|c|c|}
\hline 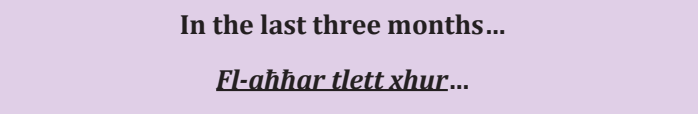 & $\begin{array}{l}\text { Very Often/ } \\
\text { Spiss Hafna } \\
\quad \text { (\%) }\end{array}$ & $\begin{array}{l}\text { FairlyOten/ } \\
\text { Spiss (\%) }\end{array}$ & $\begin{array}{l}\text { Occasioally/ } \\
\text { Kultant (\%) }\end{array}$ & $\begin{array}{c}\text { Hardly Ever/ } \\
\text { Rari (\%) }\end{array}$ & $\begin{array}{c}\text { Never/ } \\
\text { Qatt (\%) }\end{array}$ & $\begin{array}{l}\text { Not Applica- } \\
\text { ble (\%) }\end{array}$ \\
\hline $\begin{array}{l}\text { How often did you limit the kinds or amounts of food you } \\
\text { eat because of problems with your teeth or denture? } \\
\text { Kemm il-darba kellek toqghod lura mill-ammont jew } \\
\text { tip ta' ikel li tiekol minћabba problemI bi snienek jew } \\
\text { bid-dentatura? }\end{array}$ & 0 & 0 & 26.9 & 23.1 & 50 & 0 \\
\hline $\begin{array}{l}\text { How often did you have trouble biting or chewing any } \\
\text { kinds of food, such as firm meat or apples? } \\
\text { Kemm il-darba sibt diffikulta' biex tigdem jew tomghod } \\
\text { kul tip ta' ikel, bћal laћam xieref jew tuffieћ? }\end{array}$ & 3.8 & 7.7 & 34.6 & 26.9 & 26.9 & 0 \\
\hline $\begin{array}{l}\text { How often were you able to swallow comfortably? } \\
\qquad \text { Kemm il-darba stajt tibla' komdu/a? }\end{array}$ & 34.6 & 53.8 & 7.7 & 0 & 3.8 & 0 \\
\hline $\begin{array}{l}\text { How often have your teeth or dentures prevented you } \\
\text { from speaking the way you wanted? } \\
\text { Kemm il-darba sibt diffikulta' biex titkellem sew minћab- } \\
\text { ba problemI bi snienek jew bid-dentatura? }\end{array}$ & 0 & 0 & 0 & 57.7 & 42.3 & 0 \\
\hline $\begin{array}{l}\text { How often were you able to eat anything without feeling } \\
\text { discomfort? } \\
\text { Kemm il-darba stajt tiekol kollox b'kumdita'? }\end{array}$ & 19.2 & 34.6 & 15.4 & 11.5 & 19.2 & 0 \\
\hline $\begin{array}{l}\text { How often did you limit contacts with people because of } \\
\text { the condition of your teeth or dentures? } \\
\text { Kemm il-darba kellek tevita kuntatt man-nies minhabba } \\
\text { snienek jew id-dentatura? }\end{array}$ & 0 & 0 & 3.8 & 19.2 & 73.1 & 3.8 \\
\hline $\begin{array}{l}\text { How often were you pleased or happy with the looks of } \\
\text { your teeth, gums or dentures? } \\
\text { Kemm il-darba kont kuntent/a bid-dehra ta' snienek, tal- } \\
\text { hanek, jew tad-dentatura? }\end{array}$ & 0 & 23.1 & 7.7 & 7.7 & 34.6 & 26.9 \\
\hline $\begin{array}{l}\text { How often did you use medication to relieve pain or dis- } \\
\quad \text { comfort from around your mouth? } \\
\text { Kemm il-darba hadt pinnoli biex ittaffi xi ugigh f'halqek? }\end{array}$ & 0 & 3.8 & 30.8 & 19.2 & 46.2 & 0 \\
\hline 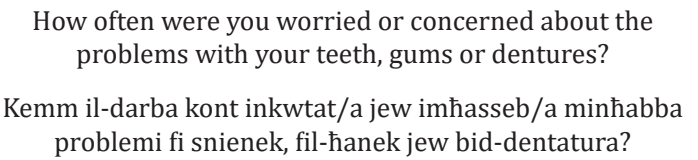 & 0 & 0 & 11.5 & 42.3 & 46.2 & 0 \\
\hline
\end{tabular}




\begin{tabular}{|c|c|c|c|c|c|c|}
\hline $\begin{array}{l}\text { How often did you feel nervous or self-conscious because } \\
\text { of problems with your teeth, gums or dentures? } \\
\text { Kemm il-darba kont anzjuz/a jew konxju/a minћabba } \\
\text { problemi fi snienek, fil-hanek jew bid-dentatura? }\end{array}$ & 0 & 11.5 & 7.7 & 23.1 & 57.7 & 0 \\
\hline $\begin{array}{l}\text { How often did you feel uncomfortable eating in front of } \\
\text { people because of problems with your teeth or dentures? } \\
\text { Kemm il-darba hassejtek skomdu/a biex tiekol quddiem } \\
\text { in-nies minhabba problemi fi snienek jew bid-dentatura? }\end{array}$ & 0 & 0 & 23.1 & 15.4 & 61.5 & 0 \\
\hline 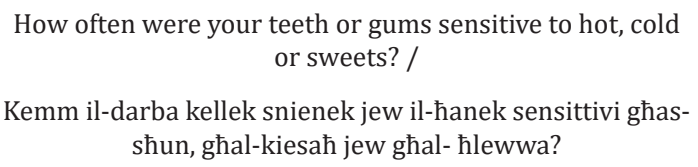 & 0 & 3.8 & 34.6 & 30.8 & 30.8 & 0 \\
\hline
\end{tabular}

Table 3: Spearman correlation between GOHAI and OHIP-14.

\begin{tabular}{|c|c|c|c|c|}
\hline \multicolumn{5}{|c|}{ Correlations } \\
\hline & & & GOHAI & OHIP14 \\
\hline \multirow{6}{*}{ Spearman's rho } & \multirow{3}{*}{ GOHAI } & Correlation Coefficient & 1.000 & $-.716^{* *}$ \\
\hline & & Sig. (2-tailed) & . & .000 \\
\hline & & $\mathrm{N}$ & 26 & 26 \\
\hline & \multirow{3}{*}{ OHIP14 } & Correlation Coefficient & $-.716^{* *}$ & 1.000 \\
\hline & & Sig. (2-tailed) & .000 & . \\
\hline & & $\mathrm{N}$ & 26 & 26 \\
\hline
\end{tabular}

Note: **. Correlation is significant at the 0.01 level (2-tailed).

\section{Gohai}

Tables 4 represent a summary of the GOHAI questionnaire scores. There was a $100 \%$ response rate. The mean score for GOHAI obtained is 46.1 out of a possible 60 . The median is 47 , the mode is 41. 46.2\% ( $=12)$ of interviewee's had a GOHAI score less than the average 46.1 meaning that they have a poorer quality of life than the rest of the sample and none of whom had a prosthesis. An increase in GOHAI scores, hence an increase in the oral health-related quality of life denture satisfaction seems to improve however due to a very small sample size of 5 individuals Spearman's correlation coefficient is not significant where $p>0.05$. There is a strong negative correlation between GOHAI and OHIP-14 where $\mathrm{p}<0.0001$, $\mathrm{r}=-0.716$, therefore as GOHAI increases, increasing quality of life, OHIP-14 scores decrease also improving quality of life. It is interesting to note that $50.0 \%(\mathrm{~N}=13)$ of individuals answered 'very often', 'often' and 'occasionally' in GOHAI questions 7 (not pleased with the looks of their teeth, mouth or dentures) even though they are visually impaired.

Table 4: The Denture Satisfaction Questionnaire results.

\begin{tabular}{|c|c|c|c|c|c|c|}
\hline & 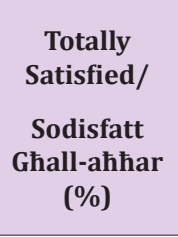 & $\begin{array}{l}\text { Very Satis- } \\
\text { fied/ } \\
\text { Sodisfatt } \\
\text { Hafna (\%) }\end{array}$ & $\begin{array}{l}\text { Reasonably } \\
\text { Satisfied/ } \\
\text { Hekk u } \\
\text { Hekk (\%) }\end{array}$ & $\begin{array}{c}\text { Not Very } \\
\text { Satisfied/ } \\
\text { Mhux } \\
\text { Sodisfatt } \\
\text { Hafna } \\
\text { (\%) }\end{array}$ & $\begin{array}{l}\text { Not At All } \\
\text { Satisfied/ } \\
\text { Lanqas } \\
\text { Xejn (\%) }\end{array}$ & $\begin{array}{c}\text { Not Applcable } \\
\text { (\%) }\end{array}$ \\
\hline $\begin{array}{l}\text { How satisfied are you with your maxillary (upper) denture? } \\
\qquad \text { Kemm inti sodisfatt/a bid-dentatura ta' fuq? }\end{array}$ & 7.7 & 0 & 7.7 & 0 & 3.8 & 80.8 \\
\hline $\begin{array}{l}\text { How satisfied are you with your mandibular (lower) den- } \\
\text { ture? } \\
\text { Kemm inti sodisfatt/a bid-dentatura t'isfel? }\end{array}$ & 0 & 0 & 3.8 & 0 & 3.8 & 92.3 \\
\hline $\begin{array}{l}\text { How satisfied are you with the retention of your maxillary } \\
\text { denture? } \\
\text { Kemm inti sodisfatt/a bil-mod kif tehel id-dentatura ta' fuq? }\end{array}$ & 7.7 & 7.7 & 3.8 & 0 & 0 & 80.8 \\
\hline $\begin{array}{l}\text { How satisfied are you with the retention of your mandibular } \\
\text { denture? } \\
\text { Kemm inti sodisfatt/a bil-mod kif tehel id-dentatura t'isfel? }\end{array}$ & 0 & 0 & 3.8 & 3.8 & 0 & 92.3 \\
\hline
\end{tabular}




\begin{tabular}{|c|c|c|c|c|c|c|}
\hline $\begin{array}{l}\text { How satisfied are you with the stability of your maxillary } \\
\text { dentures? } \\
\text { Kemm inti sodisfatt/a li d-dentatura ta' fuq hija soda } \\
\text { f'halqek? }\end{array}$ & 7.7 & 7.7 & 0 & 3.8 & 0 & 80.8 \\
\hline $\begin{array}{l}\text { How satisfied are you with the stability of your mandibular } \\
\text { denture? } \\
\text { Kemm inti sodisfatt/a li d-dentatura ta' taht hija soda } \\
\text { f'halqek? }\end{array}$ & 0 & 0 & 0 & 7.7 & 0 & 92.3 \\
\hline $\begin{array}{l}\text { How satisfied are you with the } \\
\text { comfort of your maxillary denture? } \\
\text { Kemm thossha komda d-dentatura ta' fuq? }\end{array}$ & 7.7 & 7.7 & 0 & 3.8 & 0 & 80.8 \\
\hline $\begin{array}{l}\text { How satisfied are you with the comfort of your mandibular } \\
\text { denture? } \\
\text { emm thossha komda d-dentatura t'isfel? }\end{array}$ & 0 & 0 & 0 & 3.8 & 3.8 & 92.3 \\
\hline $\begin{array}{c}\text { KHow satisfied are you with the occlusion of your dentures? } \\
\text { Kemm thossok sodisfatt/a bil-gidma tad-dentatura? }\end{array}$ & 7.7 & 3.8 & 3.8 & 0 & 3.8 & 80.8 \\
\hline $\begin{array}{l}\text { How satisfied are you with the appearance of your maxillary } \\
\text { denture? } \\
\text { Kemm thossok sodisfatt/a bid-dehra tad-dentatura ta' fuq? }\end{array}$ & 0 & 3.8 & 3.8 & 0 & 3.8 & 88.5 \\
\hline $\begin{array}{l}\text { How satisfied are you with the appearance of your mandib- } \\
\text { ular denture? } \\
\text { Kemm thossok sodisfatt/a bid-dehra tad-dentatura t'isfel? } \\
3.8\end{array}$ & 0 & 0 & 3.8 & 0 & 3.8 & 92.3 \\
\hline $\begin{array}{l}\text { How satisfied are you with the ability to speak with your } \\
\text { dentures? } \\
\text { Kemm thossok kapaci titkellem tajjeb bid-dentatura? }\end{array}$ & 11.5 & 3.8 & 0 & 3.8 & 0 & 80.8 \\
\hline
\end{tabular}

\section{Denture Satisfaction Questionnaire}

80.8\% $(\mathrm{N}=21)$ individuals are dentate, $7.7 \%(\mathrm{~N}=2)$ individuals have an upper denture whilst $11.5 \%(\mathrm{~N}=3)$ of individuals had an upper and lower denture. Table 8 shows the scores for the Denture Satisfaction questionnaire. Those individuals with an upper prosthesis only $(11.5 \%, \mathrm{~N}=3)$ had an excellent denture satisfaction score of 60, maximum score that can be obtained. Those individuals with an upper and lower denture $(7.7 \%, \mathrm{~N}=2)$ had a very average denture satisfaction score of 30.7. However, sample size for blind individuals with dentures was very small $(\mathrm{N}=5)$.

\section{Discussion}

One must keep in mind that this preliminary study consisted of a convenience sample of blind older adults who attend the governmental institution for the blind. Due to the limited population size of the Maltese Islands, the services of the various non-governmental organizations, and the governmental services, it is easier for older adults to access dental care. In fact, the government runs the same blind institution where these participants were interviewed. This institution organizes free transport to the centre in an attempt to overcome one of the major barriers. The unit offers breakfast and lunch and various activities are organised to keep them active in society. Occasionally activities are organized like open days or participation in public activities so that the Maltese community ap- preciates this sector of the population. This institution was set up in order to make sure that the blind older adult maintains an active role within society. All of the participants have support from either formal or informal carers. Thus, access to dental care is always facilitated as the carers can organise a regular dental visit. In Malta, oral health promotion has been given due importance for the past years and this is reflected in the knowledge expressed by the older adults in the study. From the study, all the participants had a good basic knowledge of what constitutes oral health and the need and importance to seek treatment.

Unfortunately, as happens most often, the older person seeks help only when he/she perceives a problem. Any study carried out usually creates more awareness about certain issues. In fact, the governmental institution supported this study and it increased oral health awareness to both the older adults themselves and their formal/informal carers. The interpretation of the individual's oral health status, known as self-perceived oral health status was analysed in this study using OHIP-14, GOHAI and the Denture Satisfaction Questionnaires. An individual's prior life experiences as well as their cultural, social and historical background will affect their self-perceived oral health status [14]. Therefore, individuals with the same oral health status, may perceive the oral health-related quality of life (OHQoL) differently [15]. Older adults who perceive poor oral health but at the same time have poor expectations may 
not view oral health as having an impact on their quality of life. Similarly older adults who have high expectations may have a minor oral health problem and rate their OHQoL as poor [16].

Locker et al. [17], reported that GOHAI is able to detect the impact of oral disease more than OHIP-14 as fewer participants had 'never' responses also referred to as zero scores [17]. Similarly in this study the difference in 'zero' scores is substantial where 75\% of participants reported a 'zero' score in OHIP-14 whilst only $18.4 \%$ in GOHAI indicating a better representation of the oral health related quality of life in GOHAI. Spearman correlation coefficient shows that there is a strong negative correlation between GOHAI and OHIP-14 where $\mathrm{p}<0.0001, \mathrm{r}=-0.716$, therefore as GOHAI increases, increasing quality of life, OHIP-14 scores decrease also improving quality of life. OHIP-14 and GOHAI scores show a very good oral health-related quality of life where OHIP-14 scored 5.7 from a worst possible score of 56 and GOHAI scored 46.1 from the best possible score of 60. International studies using measures such as GOHAI and OHIP-14 also report a good perceived oral health-related quality of life [17-20] despite the poor oral health status. In general the oral health-related quality of life of the participants was good, however it has been shown that older adults seem to resign themselves to accept and adapt to their oral condition with the notion of growing old unless an acute episode occurs such as a facial swelling [19].

Piuvezam and de Lima, mention the "secondarization of oral problems" where multiple bio-psycho-social problems take precedence over oral health [15]. In fact, Santucci and Attard [21] report an OHIP-14 score of 3.8, a GOHAI score of 54.5 and a Denture Satisfaction score of 42.8 in a group of 278 institutionalised Maltese older adults with an average age of 83.6 years [21]. The better reported oral health-related quality of life may have been achieved either because the sample size was larger or as multiple bio-psycho-social problems occur with increasing age, the secondarization of oral problems also increases, hence the perception of a better oral health-related quality of life. OHIP-14 scores showed that $38.5 \%$ $(\mathrm{N}=10)$ of participants had a score worse than the average score of 5.7 indicating a worse oral health-related quality of life than the rest of the participants. None of the 10 participants $(\mathrm{N}=10)$, who had an OHIP-14 score higher than the average of 5.7 had dentures possibly indicating a poor oral health status such as caries and periodontal disease.

Table 3 indicates that with reduced denture satisfaction scores, the oral health-related quality of life also decreases (increasing OHIP-14) however this was not statistically significant ( $p>0.05$ ) as sample size was too small. Those participants who reported a reduced oral health-related quality of life when compared to the other participants may have a poor oral health status and require dental treatment due to a number of barriers which they are not managing to surmount. $46.2 \%(\mathrm{~N}=12)$ of interviewees had a GOHAI score less than the average 46.1 meaning that they have a poorer quality of life than the rest of the sample and none of whom had a prosthesis. With an increase in GOHAI scores, hence an increase in the oral health-related quality of life, denture satisfaction seems to improve however due to a very small sample size of 5 individuals Spearman's correlation coefficient is not significant where $\mathrm{p}>0.05$.

In OHIP-14, 34.6\% of individuals ( $\mathrm{N}=9$ ), reported 'very often', 'often' and 'occasionally', indicating worst oral health-related quality of life in questions 3 (painful episodes) and 4 (uncomfortable eating). It is interesting to note that $15.4 \%(\mathrm{~N}=4)$ stated that they are fairly often conscious because of their teeth, mouth or dentures due to their visual impairment with $11.5 \%(\mathrm{~N}=3)$ claiming that life in general was less satisfying, whilst in GOHAI, 50.0\% (N=13) of individuals answered 'very often', 'often' and 'occasionally' in question 7 (not pleased with the looks of their teeth, mouth or dentures) even though they are visually impaired. Smiling people are presumed to be more sociable, sincere and attractive [22] and an inability to reach good dental aesthetics may lead to feelings of embarrassment, diminished self-confidence, failure and shame [23]. Older adults with deformities of the mouth such as in stroke patients, head and neck cancer or decayed teeth may attract rude curiosities where the older adults would feel stigmatized leading to avoidance of social situations to minimize their psychosocial distress [24-26].

Caspian reports that question 3 (swallowing problems) from GOHAI inflated the results [27]. Swallowing was included in GOHAI as to gauge the prevalence of xerostomia in older adults. However in this study, $90.9 \%$ were always, often or occasionally able to swallow comfortably. The $9.1 \%$ who have swallowing problems should be addressed by excluding xerostomia and odontogenic problems, liaising with medical officers and pharmacists to switch to less xerogenic drugs and referral to a speech language pathologist for further management of the swallowing problems if necessary. Gerdin et al. [29] report that dry mouth is significantly associated with oral health related quality of life stressing the importance of monitoring xerostomia in the care of older adults [28].

\section{Denture Satisfaction Questionnaire}

The lowest denture satisfaction scores (30.7 from a possible 60 ) were obtained by individuals who wear a lower denture, however sample size for blind individuals with dentures was very small $(\mathrm{N}=5)$. This was also observed in Santucci and Attard [21] where poorest satisfaction scores were obtained from mandibular dentures due to ridge resorption leading to a reduced stability and retention of the prosthesis [13]. Frank et al., (1998) in a study on removable mandibular partial dentures found that individuals were mostly dissatisfied when there was an opposing maxillary removable denture [29]. In individuals where mandibular dentures are not satisfactory, implant-retained dentures may be advocated, however in visually impaired individuals, oral health maintenance may be more challenging [30,31]. The average denture age of this group of participants is not known however Allen and McMillan [32] suggest, older adults who have worn dentures for over 10 years of age are less likely to complain [31].

\section{Conclusion}

This area of research deserves a more extensive investigation that will include more individuals as well as a dental examination. 
Totally blind older adults represent other older adult communities who might be experiencing other forms of impairments and disabilities. The most important concept is to ensure a good oral health-related quality of life. This can only be achieved by adequately trained dental personnel including the dental surgeon and dental hygienist who create awareness amongst the older adults and their carers by regularly organising oral health promotion activities. Good oral hygiene practice is the essence to prevent dental problems. Gerodontologists have an essential role to remove any barriers that may be impeding the visually-impaired older adult from seeking and receiving the appropriate dental care and treatment. In fact, the health personnel who run this institute were very encouraging for future visits, as most of the time, the medical and social issues exhaust their resources. Visually impaired older adults may give more priority to their disability than their oral care therefore interdisciplinary action will empower the older adult to seek the necessary care required from various dental, social and medical professionals.

\section{References}

1. Ebrahim S, Kalache A (1996) Epidemiology in old age. BMJ Publishing Group pp. 331-343.

2. Mahoney EK, Kumar N, Porter SR (2008) Effect of visual impairment upon oral health care: A Review. British Dental Journal 204(2): 63-67.

3. (2013) World Health Organisation. Fact Sheet No. 282.

4. American Foundation for the Blind. Expanding possibilities for people with vision loss.

5. Schembri A, Fiske J (2001) The implications of visual impairment in an older adult's population in recognizing oral disease and maintaining oral health. Special Care Dentistry 21(6):222-226.

6. Sheila K, Gary S (2002) Rubin How Does Visual Impairment Affect Performance on Tasks of Everyday Life? Arch Ophtalmol 210(6): 774 780.

7. Aljoharah Abdullah Al-Sinaidi (2003) Oral hygiene practices and periodontal health status of visually impaired Saudi adults in Riyadh, Saudi Arabia. Pakistan Oral and Dental Journal 33(1): 82-86.

8. Slade GD, Spencer AJ (1994) Development and evaluation of the Oral Health Impact Profile. Community Dental Health 11(1): 3-11.

9. Slade GD (1997) Derivation and validation of a short-form oral health impact profile. Community Dentistry and Oral Epidemiology 25(4): 284 290.

10. Atchison K A, Dolan TA (1990) Development of the Geriatric Oral Health Assessment Index. Journal of Dental Education 54(11): 680-687.

11. Allen PF, Mc Millan AS (2003) A review of the Functional and Psychosocial Outcomes of Edentulousness Treated with Complete Replacement Dentures. Journal of The Canadian Dental Association 69(10): 662.

12. (2007) National Statistics Office, Census of Population and Housing 2005, Volume 1: National Statistics Office, Population-Valletta, Malta, USA, pp. 216

13. Santucci D, Camilleri L, Attard N (2014) Development of a Maltese version of oral health-associated questionnaires: OHIP-14, GOHAI, and the Denture Satisfaction Questionnaire. International Journal of Prosthodontics 27(1): 44-449.

14. Gilbert L (1994) Social factors and self-assessed oral health in South
Africa. Community Dentistry and Oral Epidemiology 22(1): 47-51.

15. Piuvezam G, de Lima KC (2012) Self-perceived oral health status in institutionalized older adults in Brazil. Archives of Gerontology and Geriatrics 55(1): 5-11.

16. Kotzer RD, Lawrence HP, Clovis JB, Matthews DC (2012) Oral healthrelated quality of life in an aging Canadian population. Health Quality of Life Outcomes 10: 50.

17. Locker D, Matear D, Lawrence H, Payne B (2001) Comparison of the GOHAI and OHIP-14 as measures of the oral health-related quality of life of the older adults. Community Dentistry and Oral Epidemiology 29(5): 373-381.

18. Locker D, Clarke M, Payne B (2000) Population Self-perceived Oral Health Status, Psychological Well-being, and Life Satisfaction in an Older Adult. Journal of Dental Research 79(4): 970-975.

19. Silva SRC, Fernandes RAC (2001) Self-perception of oral health status by the older adults. Rev Saúde Pública 35: 359-455.

20. Martins AM, Eleutério de Barros L, Barreto SM, Pordeus IA (2009) Objective and subjective factors related to self-rated oral health among the older adults. Cadernos de Saúde Pública 25(2): 421-435.

21. Santucci D, Attard N (2015) The oral health-related quality of life in state institutionalised older adults. International Journal of Prosthodontics 28(4): 402-411.

22. Reis HT, Wilson IM, Monestere C, Bernstein S, Clark K, et al. (1990) What is smiling is beautiful and good. European Journal of Social Psychology 20(3): 259-267.

23. Mc Kinley NM, Hyde JS (1996) The Objectified Body-Conscious Scale: Development and Validation. Psychology of Women Quarterly 20: 181215.

24. Mac Entee MI, Müller F, Wyatt C (2011) Oral Healthcare and the Frail Elder. A Clinical Perspective. Blackwell Publishing Ltd, New Jersey, USA.

25. Newell RJ (1999) Altered body image: a fear-avoidance model of psychosocial difficulties following disfigurement. Journal of Advanced Nursing 30(5):1230-1238.

26. Rumsey N, Clarke A, Musa M (2002) Altered body image: The psychosocial needs of patients. British Journal of Community Nursing 7: 563-566.

27. Rumsey N, Clarke A, White P, Wyn Williams M, Garlick W (2004) Altered body image: Appearance related concerns of people with visible disfigurement. Journal of Advanced Nursing 48(5): 23-27.

28. Caspian J (2012) Validation of Persian version of GOHAI. Journal of dental research 1(2): 8-17.

29. Gerdin EW, Jonsson M, Aronsson K, Johansson I (2005) Impact of dry mouth conditions on oral health-related quality of life in older people. Gerodontology 22(4): 219-226.

30. Frank RP, Milgrom P, Leroux BG, Hawkins NR (1998) Treatment outcomes with mandibular removable partial dentures: a population-based study of patient satisfaction. Journal of Prosthetic Dentistry 80(1): 36-45.

31. Huumonen S, Haikola B, Oikarinen K, Söderholm AL, Remes Lyly T, Spilà K (2012) Residual ridge resorption, lower denture stability and subjective complaints among edentulous individuals. Journal of Oral Rehabilitation 39(5): 384-390.

32. Allen PF, Mc Millan AS (2003) A longitudinal study of quality of life outcomes in older adults requesting implant prostheses and complete removable dentures. Clinical Oral Implantology Research 14(2): 173179. 
(C) $\oplus$ This work is licensed under Creative

Submission Link: https://biomedres.us/submit-manuscript.php

Assets of Publishing with us
BESEARCHES $\quad \begin{aligned} & \text { Global archiving of articles } \\ & \text { - Immediate, unrestricted online access } \\ & \text { - Rigorous Peer Review Process }\end{aligned}$

